\title{
Application of ultrasound-guided bilateral erector spinae plane block in lumbar spinal surgery
}

\author{
Jiang Wang, Yao Lu \\ Department of Anesthesiology, the First Affiliated Hospital of Anhui Medical University, Hefei 230022, China \\ Correspondence to: Dr. Yao Lu, MD, PhD. Department of Anesthesiology, the First Affiliated Hospital of Anhui Medical University, Hefei, 230022, \\ China. Email: luyao-mz@163.com.
}

Submitted Jan 27, 2020. Accepted for publication Apr 09, 2020.

doi: 10.21037/apm-20-287

View this article at: http://dx.doi.org/10.21037/apm-20-287

Plane blocks have gained popularity with the recent introduction of ultrasonography into the practice of regional anesthesia. These blocks are frequently applied because of their ease of application, low complication rates, effective postoperative analgesia, and reduction in opioid consumption. The erector spinae plane block (ESPB) was first described for use in chronic thoracic neuropathic pain in 2016 (1), and since then, it has been indicated as an effective regional anesthesia technique for preventing postoperative pain in various surgical procedures (2-6).

Posterior lumbar fusion is a common procedure for the treatment of lumbar degenerative diseases. However, posterior lumbar fusion is traumatic and the postoperative pain is severe, which affects the physiological functions of circulation and respiration as well as seriously affects early activities and functional exercises. The combination of general anesthesia and a regional nerve block can significantly reduce the stress response of patients, reduce the dosage of general anesthetics and analgesics, shorten the postoperative recovery time, and reduce general anesthesiarelated complications. A previous study showed that ultrasound-guided ESPB could provide sufficient analgesia during lumbar spinal fusion surgery and could significantly reduce opioid and anesthesia consumption (7).

The erector spinae muscles comprise a group of muscles and from the outside to the inside are the Iliocostalis, Longissimus, and Spinalis muscles. They are located on both sides of the spine, where they extend from the skull to the pelvis and sacral regions, from the spinous to the transverse processes, and finally, to the ribs. Each upper lumbar nerve divides into a dorsal and ventral branch at the exit of its intervertebral foramen. The dorsal ramus travels posteriorly through the costotransverse foramen and ascends into the erector spinae muscles. Here, the dorsal ramus is divided into lateral and medial branches, and the medial branch continues to rise to the superficial position through the rhomboid and rectus muscles before ending in the posterior cutaneous branch (Figure 1A). The mechanism of the ESPB is unclear; however, the primary mechanism of local anesthetics is that they likely block the posterior branch of the spinal nerve in the fascial space.

Ultrasound-guided bilateral ESPB was performed as follows. The patient was placed in a prone position and the appropriate T12 vertebral body level was determined by surface dissection or ultrasound (counting from the 12th rib). High-frequency ultrasound transducer was placed in the longitudinal sagittal position $3 \mathrm{~cm}$ from the midline to determine the tip of the transverse process. Thereafter, the T12 transverse process and trapezius, rhomboid major, and erector spinae muscles were identified from the surface. Using the in-plane technique, the needle was inserted from a caudal to a cranial direction, and the needle reached through the interfascial plane between the erector spinae muscles and the T12 transverse process (Figure 1B). The ESPB was administered by the injection of $40 \mathrm{~mL}$ of $0.375 \%$ ropivacaine $(20 \mathrm{~mL}$ injected into each side) into the interfascial plane between the rhomboid major and erector spinae muscles (Figure 1C). A low-frequency ultrasound transducer is more suitable for lumbar nerve block, as the erector spinae muscles may be deep (depth $>4 \mathrm{~cm}$ ).

In a recent study, ESPB performed bilaterally at the T12 vertebral level provided effective analgesia after lumbar spinal fusion surgery. The area of hypoalgesia was determined to be from T8-10 to L3-4 and from the left 

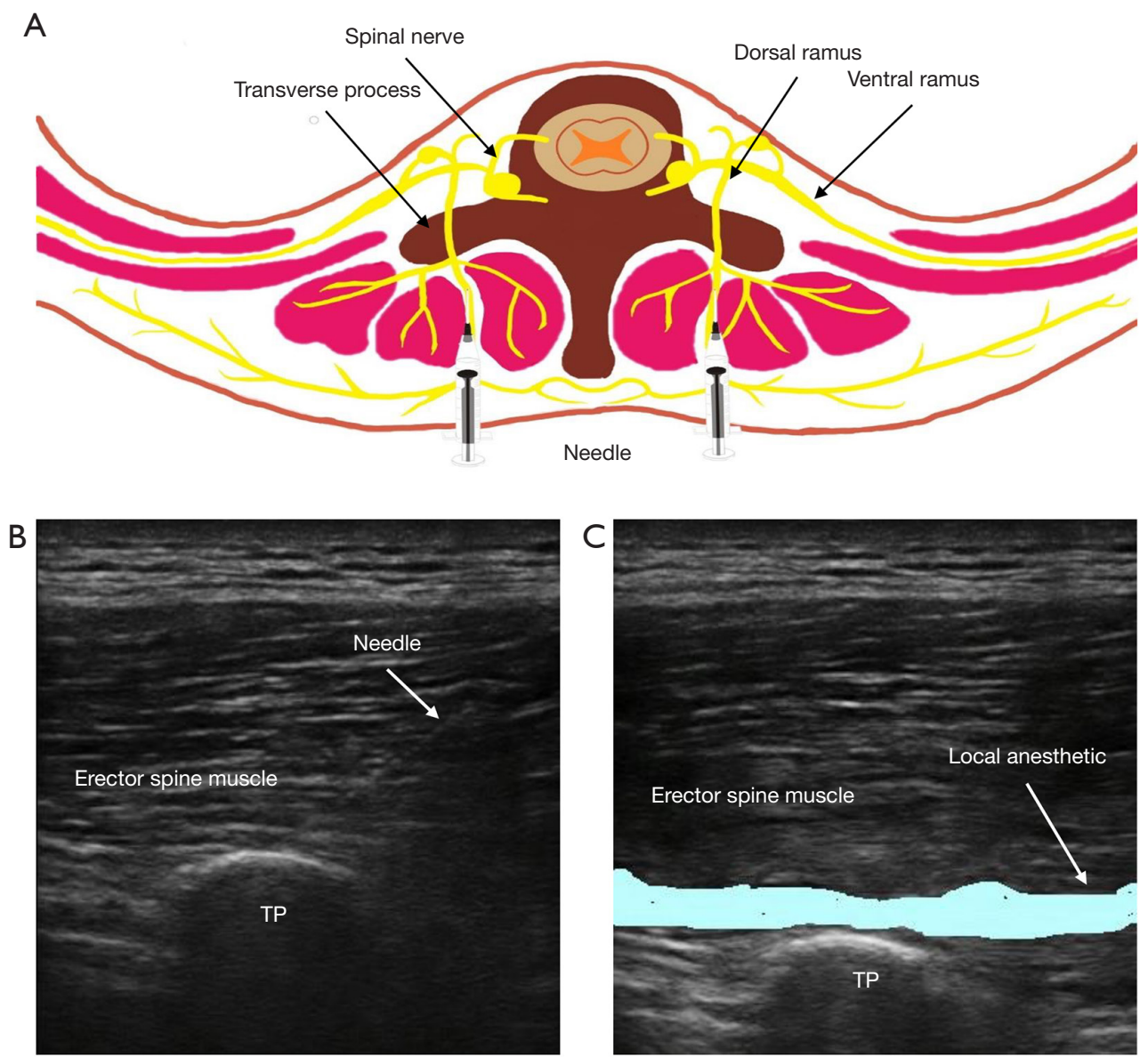

Figure 1 Sketch of the erector spinae plane block. (A) Anatomy of the ventral and dorsal branches of the spinal nerve and the relationship between the spinal nerve and the erector spinae muscles; (B) ultrasound image before the administration of local anesthetic; (C) ultrasound image after the administration of local anesthetic. TP, transverse processes.

posterior axillary line to the right posterior axillary line. Ten minutes later, the area of hypoalgesia was from T6-8 to L5/ $\mathrm{S} 1$ and from the left to the right posterior axillary line in the posterior lumbar region (7).

The ESPB is simple and easy to perform. This method, when performed before the start of surgery, provides longlasting postoperative analgesia. Moreover, ESPB plays a critical role in the early recovery and early mobilization of patients. Therefore, the ultrasound-guided bilateral ESPB technique is worth promoting in lumbar spinal surgery.

\section{Acknowledgments}

Funding: This work is supported by Key Project of Excellent Youth in Higher Education Institution of Anhui Province (gxyqZD2018028).

\section{Footnote}

Conflicts of Interest: Both authors have completed the ICMJE uniform disclosure form (available at http://dx.doi. org/10.21037/apm-20-287). The authors have no conflicts of interest to declare.

Ethical Statement: The authors are accountable for all aspects of the work in ensuring that questions related to the accuracy or integrity of any part of the work are appropriately investigated and resolved.

Open Access Statement: This is an Open Access article distributed in accordance with the Creative Commons Attribution-NonCommercial-NoDerivs 4.0 International License (CC BY-NC-ND 4.0), which permits the non- 
commercial replication and distribution of the article with the strict proviso that no changes or edits are made and the original work is properly cited (including links to both the formal publication through the relevant DOI and the license). See: https://creativecommons.org/licenses/by-nc-nd/4.0/.

\section{References}

1 Forero M, Adhikary SD, Lopez H, et al. The Erector Spinae Plane Block: A Novel Analgesic Technique in Thoracic Neuropathic Pain. Reg Anesth Pain Med 2016;41:621-7.

2 Thota RS, Mukherjee D. Continuous erector spinae plane block as an anesthetic technique for breast cancer surgery. J Anaesthesiol Clin Pharmacol 2019;35:420-1.

3 Lin C, Gill R, Kumar K. Bilateral lower thoracic erector spinae plane block in open abdominal gynecologic oncology surgery: a cases series. Rev Bras Anestesiol

Cite this article as: Wang J, Lu Y. Application of ultrasoundguided bilateral erector spinae plane block in lumbar spinal surgery. Ann Palliat Med 2020;9(3):1282-1284. doi: 10.21037/apm20-287
2019;69:517-20.

4 Ibrahim M, Elnabtity AM. Analgesic efficacy of erector spinae plane block in percutaneous nephrolithotomy: A randomized controlled trial. Anaesthesist 2019;68:755-61.

5 Rincón C, Moreno DA, Moore A. Erector spinae plane block for post- cesarean delivery analgesia. Int J Obstet Anesth 2020;41:120-2.

6 Chen N, Qiao Q, Chen R, et al. The effect of ultrasoundguided intercostal nerve block, single-injection erector spinae plane block and multiple-injection paravertebral block on postoperative analgesia in thoracoscopic surgery: A randomized, double-blinded, clinical trial. J Clin Anesth 2020;59:106-11.

7 Chen K, Wang L, Liu X, et al. Ultrasound-Guided Erector Spinae Plane Block Reduces Perioperative Opioid Consumption in Lumbar Spinal Fusion. Am J Ther 2019. [Epub ahead of print]. 